\title{
Coloration, Anthocyanin Concentration, and Growth of Croton (Codiaeum variegatum L.) as Affected by Cotton Gin Trash Compost Use in the Potting Medium
}

\author{
Maria Papafotiou ${ }^{1,4}$, Barbara Avajianneli ${ }^{3}$, and Costas Michos ${ }^{3}$ \\ Laboratory of Floriculture and Landscape Architecture, Department of Crop \\ Science, Agricultural University of Athens, Iera Odos 75, 11855 Athens, \\ Greece
}

\section{Iordanis Chatzipavlidis ${ }^{2}$ \\ Laboratory of Agricultural Microbiology, Department of Agricultural Biotechnology, Agricultural University of Athens, Iera Odos 75, 11855 Athens, Greece}

Additional index words. anthocyanins, foliage color, foliage potted plants, ornamentals, horticultural substrate, growth medium, growing mix

\begin{abstract}
Compost from cotton gin trash was evaluated as a peat substitute in Codiaeum variegatum $\mathrm{L}$. production. Rooted cuttings were grown for 8 months in media containing cotton gin trash compost, sphagnum peatmoss, and perlite in $1: 3: 4,1: 1: 2$, and 3:1:4 ratios respectively, and their growth was compared with a control medium of 1 peat : 1 perlite (by volume). Even when $75 \%$ of peat in the control medium was replaced by cotton gin trash compost, plant height, leaf number, and leaf size were unaffected, whereas root dry weight was increased in the medium with $25 \%$ peat replacement. Although replacement of peat by cotton gin trash compost did not affect quantitative characteristics of croton foliage growth, it affected the foliage color, as plants in media with cotton gin trash compost had more areas colored red in their leaves. The increase of red coloration was proportional to the increase of cotton gin trash compost in the medium. The phenomenon was more intense in the lower leaves than the apical ones. Anthocyanin concentration measurements showed that the gradual increase of cotton gin trash compost level in the growth medium caused a gradual increase of the anthocyanin concentration in the leaves. This effect is discussed in relation to chemical properties of the media, as electrical conductivity, $\mathrm{pH}$, and nutrient concentrations. The gradual increase of cotton gin trash compost level caused an analogous increase of $N, P$, and $K$ concentrations in the medium. Also, media with cotton gin trash compost had high electrical conductivity at the beginning of the culture period, related to the cotton gin trash compost level, which was reduced to values similar to that in the control medium after 50 days of culture. Na concentration in the media ranged similarly to electrical conductivity. The $\mathrm{pH}$ was positively related to cotton gin trash compost level, and media with a high cotton gin trash compost level had increased $\mathrm{pH}$ during the culture period compared with the control.
\end{abstract}

Potted ornamental plants are grown mostly in substrates that consist of peat and an inorganic material like perlite and vermiculite. In recent years the use of peat in horticulture has been under discussion because it is considered a nonrenewable resource that should be preserved. A parallel environmental issue is the disposal of agricultural wastes. Composts from agricultural wastes have the potential to replace a significant proportion of peat in the

Received for publication 25 June 2006. Accepted for publication 13 Sept. 2006.

${ }^{1}$ Assistant Professor.

${ }^{2}$ Lecturer.

${ }^{3}$ Graduate

${ }^{4}$ To whom reprint requests should be addressed; e-mailmpapaf@aua.gr bracts (e.g., poinsettia), an increase of the red coloration was observed when grown in substrates that contained certain composts (pers. obs.). Because color is a major parameter of plant marketability, the current study was carried out to investigate the effect of cotton gin trash compost (CGC) on plant growth and, in particular, leaf color of croton (Codiaeum variegatum L.). Croton leaves bear yellow pigmentation when they are young (mainly around the mid rib and the veins), which changes into red as the leaves age. The upper leaves of the plant are green-yellow, the lower are green-red, and the middle ones have all three colors. We found no reports in the literature on the type of pigments involved in the coloration of croton leaves; thus, anthocyanins, which usually are responsible for red coloration in plant tissues (Mulder-Krieger and Verpoorte, 1994), were examined in this work.

Production of anthocyanins appears to be related to the accumulation of excess carbohydrate, viral or fungal infection, treatment with growth regulators or wounding, temperature, and light. Some of the color variations may be correlated to acylation of anthocyanins, copigmentation with other flavonoids, and complex formation with metal ions (e.g., anthocyanins with unusual hydroxylation patterns contribute to yellow coloration). The $\mathrm{pH}$ of the vacuolar sap is correlated to all these complex formations of anthocyanins (Harborne, 1980; Mulder-Krieger and Verpoorte, 1994).

\section{Materials and Methods}

Rooted cuttings of $C$. variegatum $\mathrm{cv}$. Nor$\mathrm{ma}, 50 \mathrm{~d}$ old, about $6 \mathrm{~cm}$ height (from rooting medium surface to the upper visible node), were potted singly on 15 July in 14-cm (1300$\mathrm{mL}$ ) black plastic pots, in the following potting media (ratios by volume): 0 CGC $: 1$ peat : 1 perlite ( $0 \%$ CGC, control), 1 CGC : 3 peat : 4 perlite $(12.5 \%$ CGC concentration $-25 \%$ peat replacement by CGC), 1 CGC : 1 peat : 2 perlite $(25 \%$ CGC concentration- $-50 \%$ peat replacement by CGC), and 3 CGC : 1 peat : 4 perlite $(37.5 \%$ CGC concentration- $75 \%$ peat replacement by CGC). The 1 peat : 1 perlite medium used as a control is one of the most commonly used media for foliage plant production. A sphagnum peatmoss was used with a degree of humification $\mathrm{H}_{3}-\mathrm{H}_{5}$ (Stanek and Silc, 1977) and a $\mathrm{pH}$ of 3.4 to 3.7 . The $\mathrm{pH}$ value of the control medium was low and was adjusted to 5.9 with dolomitic limestone. The growth medium of potted ornamentals (Burger et al., 1997; Papafotiou et al., 2001a, b, 2004, 2005; Wang and Blessington, 1990). In experiments on plants with red-colored leaves or
Table 1. Effect of peat replacement in the growth medium by CGC at the percentages shown on plant height, leaf number, leaf dimensions, and root dry weight of $C$. variegatum $\mathrm{cv}$. Norma.

\begin{tabular}{lccccc}
\hline $\begin{array}{l}\text { Peat replacement } \\
(\%)\end{array}$ & $\begin{array}{c}\text { Plant height } \\
(\mathrm{cm})\end{array}$ & Leaf number & $\begin{array}{c}\text { Leaf length } \\
(\mathrm{cm})\end{array}$ & $\begin{array}{c}\text { Leaf width } \\
(\mathrm{cm})\end{array}$ & $\begin{array}{c}\text { Root dry } \\
\text { weight }(\mathrm{g})\end{array}$ \\
\hline 0 & $20.5 \mathrm{a}$ & $23.2 \mathrm{a}$ & $16.1 \mathrm{a}$ & $7.5 \mathrm{ab}$ & $3.4 \mathrm{~b}$ \\
25 & $20.8 \mathrm{a}$ & $24.4 \mathrm{a}$ & $16.6 \mathrm{a}$ & $7.2 \mathrm{~b}$ & $4.7 \mathrm{a}$ \\
50 & $18.1 \mathrm{a}$ & $24.5 \mathrm{a}$ & $17.3 \mathrm{a}$ & $8.1 \mathrm{ab}$ & $3.7 \mathrm{~b}$ \\
75 & $19.7 \mathrm{a}$ & $24.0 \mathrm{a}$ & $17.8 \mathrm{a}$ & $8.3 \mathrm{a}$ & $3.9 \mathrm{~b}$ \\
Significance $^{\mathrm{z}}$ & NS & NS & NS & $\mathrm{Q}^{*}$ & $\mathrm{C}^{* * *}$ \\
\hline
\end{tabular}

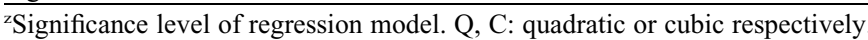

Mean separation within columns by Tukey HSD at $P=0.05$.

NS, ${ }^{* * * * *}$ Nonsignificant, significant at $P<0.05$ or $<0.001$ respectively.

Leaf width: $\mathrm{y}=6.764+0.34 \mathrm{x}+0.136(\mathrm{x}-2.525)^{2}, r^{2}=0.221$

Root dry weight: $\mathrm{y}=7.673-1.412 \mathrm{x}-0.146(\mathrm{x}-2.5)^{2}+0.653(\mathrm{x}-2.5)^{3}, r^{2}=0.639$. 
CGC composting process used was described by Balis et al. (1994). At maturity, CGC was found to contain $86.8 \mathrm{ppm} \mathrm{NH} 4-\mathrm{N}, 37.6 \mathrm{ppm}$ $\mathrm{NO}_{3}-\mathrm{N}, 61,200 \mathrm{ppm} \mathrm{Ca}, 14,900 \mathrm{ppm} \mathrm{Mg}$, 24,100 ppm K, 5600 ppm Na, and 4500 ppm $\mathrm{P}$ over dry weight.

The plants were grown for 8 months (15 July-15 Mar.) in a heated glasshouse under natural photoperiod and about 130 $\mu \mathrm{mol} \cdot \mathrm{m}^{-2} \cdot \mathrm{sec}^{-1}(7000 \mathrm{~lx})$ light intensity at midday. Average monthly minimum night temperature measured in the glasshouse during the experimental period ranged from 20 to $26^{\circ} \mathrm{C}$ and average monthly maximum day temperature ranged from 24 to $33{ }^{\circ} \mathrm{C}$. The plants were irrigated to ensure leaching from the pot, with frequency depending on green house temperature, solar radiation and plant age (daily in July-August, every second day in September, and every 2-3 d the following months). The plants were fertilized weekly until the end of the experiment with a complete water-soluble fertilizer (Nutrileaf 60, 20-20-20, Miller Chemical and Fertilizer Corp., Hanover, Penn.) 20 N-11.27 P-16.6 K-0.025 Mg-0.02 B-0.05 Cu-0.10 Fe-0.05 Mn-0.001 Mo-0.05 Zn (2 g.L $\mathrm{L}^{-1}, 400$ $\mathrm{mg} \cdot \mathrm{L}^{-1} \mathrm{~N}, 100 \mathrm{~mL}$ of solution per pot).

Every $50 \mathrm{~d}$ during the experimental period, measurements of the media $\mathrm{pH}$ and electrical conductivity (EC) were made in 1:5 volume water extracts (Federal Compost Quality Assurance Organization, 1994), as well as measurements of total N (McGill and Figueiredo, 1993), P, K, and $\mathrm{Na}$ (Karam, 1993) concentration. $\mathrm{P}, \mathrm{K}$, and $\mathrm{Na}$ were extracted by $\mathrm{HNO}_{3}$. $\mathrm{P}$ was quantified by spectrophotometry (Milton Roy, Spectronic 401, Ivyland, $\mathrm{Pa}$.), and $\mathrm{K}$ and $\mathrm{Na}$ by flame photometry (Corning, Flame Photometer 410, Corning, N.Y.). The results were expressed on the substrate by weight. At the end of the experiment, the plant height (from pot rim to the upper visible node), leaf number, leaf length, leaf width, root dry weight, as well, as leaf color and anthocyanin concentration of the basal, middle, and apical leaves of the plant were measured. Plant height increase was calculated as the difference between cutting height and final plant height. Leaf color measurements were made in six leaves per plant at a vertical (tip to base). In each leaf, five measurements at predetermined positions of the lamina were taken with a Minolta chroma meter CR-300 (Conica Minolta Greece, Athens). The parameter "a" of the chroma meter that indicates red coloration was used. The five positions of color measurements were one in the middle of the leaf lamina next to the mid rib, and two at the basal and two at the apical part of the leaf at the center of the lamina left and right to the mid rib. Anthocyanins were extracted from the leaves with $\mathrm{HCl}$ in methanol [1\% v/v solution (Harborne, 1998)], quantified by adsorption spectrophotometry (Shimatzu $160 \mathrm{~A}$, Shimatzu, Kyoto, Japan) at $530 \mathrm{~nm}$, and their concentration was expressed on the leaf surface. There were 20 plants per treatment; 10 were used for plant growth and leaf color measurements of which half of them

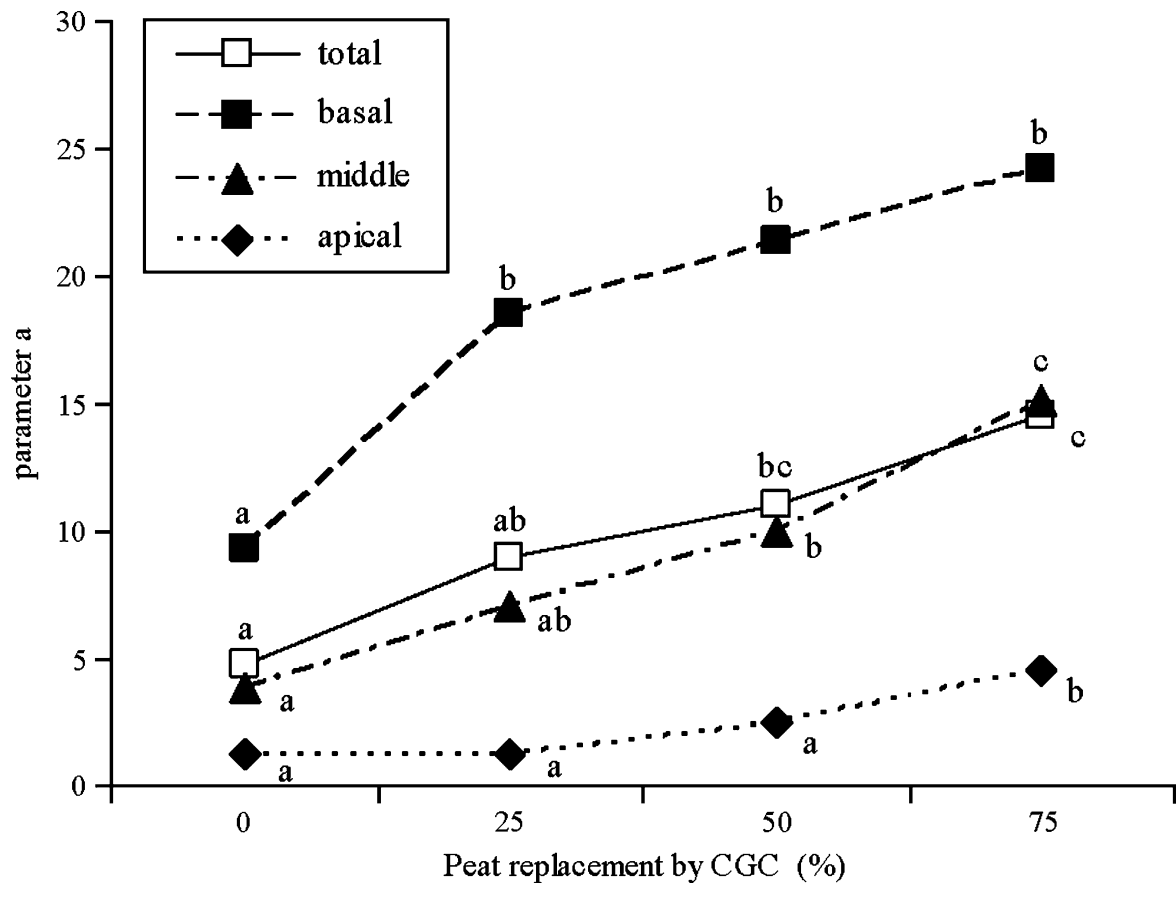

Fig. 1. Effect of peat replacement in the growth medium by cotton gin trash compost (CGC) at the percentages shown on red coloration (parameter "a" of the chroma meter) in the basal, middle, apical, and total leaves of $C$. variegatum cv. Norma. Mean separation on line by Tukey HSD at $P=0.05$. Regression model for basal leaves: $\mathrm{y}=6.457+4.766 \mathrm{x}, r^{2}=0.40, P<0.001$. Regression model for middle leaves: $\mathrm{y}=-0.147+3.666 \mathrm{x}, r^{2}=0.40, P<0.001$. Regression model for apical leaves: $\mathrm{y}=-0.291+$ $1.073 \mathrm{x}, r^{2}=0.25, P<0.001$. Regression model for total leaves: $\mathrm{y}=2.007+3.169 \mathrm{x}, r^{2}=0.15, P<0.001$.

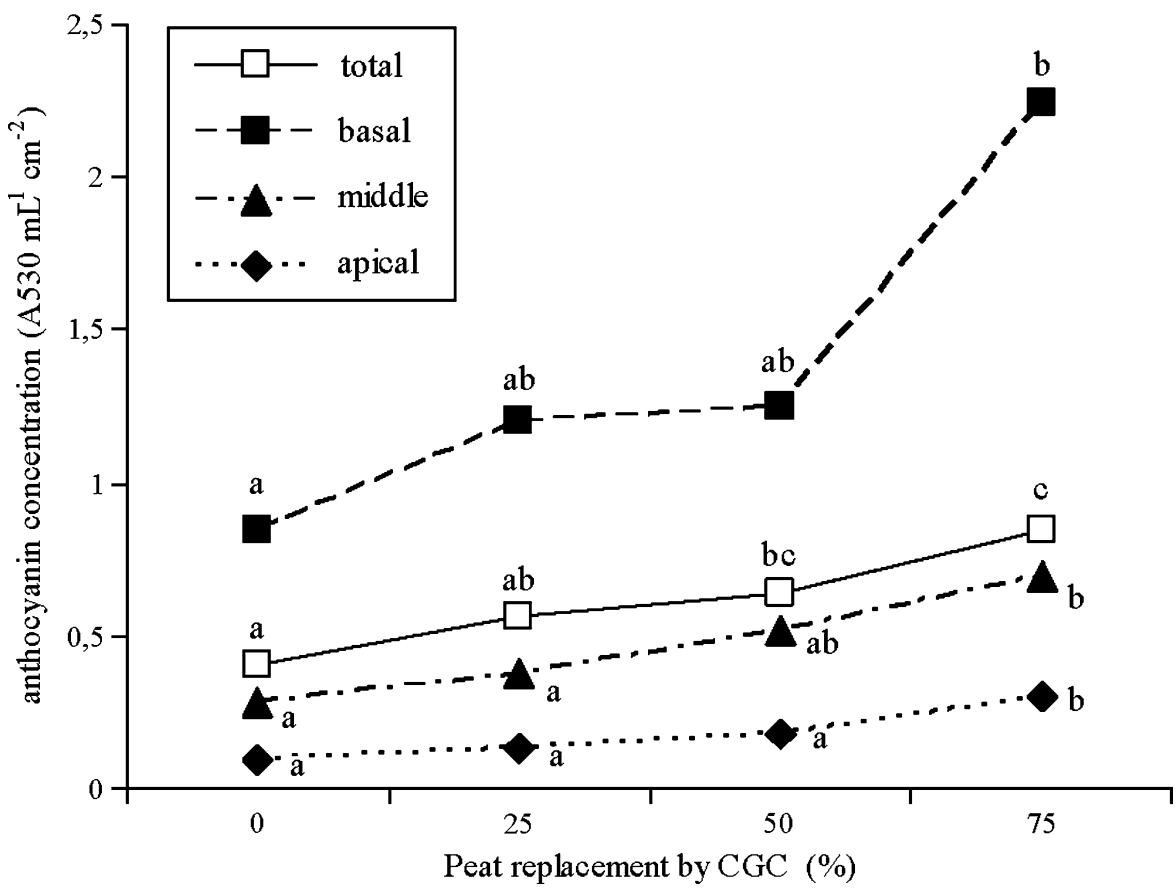

Fig. 2. Effect of peat replacement in the growth medium by cotton gin trash compost (CGC) at the percentages shown on anthocyanin concentration in the basal, middle, apical, and total leaves of $C$. variegatum $\mathrm{cv}$. Norma. Mean separation on line by Tukey HSD at $P=0.05$. Regression model for basal leaves: $\mathrm{y}=0.409+0.370 \mathrm{x}, r^{2}=0.37, P<0.01$. Regression model for middle leaves: $\mathrm{y}=0.116+0.141 \mathrm{x}$, $r^{2}=0.48, P<0.001$. Regression model for apical leaves: $\mathrm{y}=0.006+0.069 \mathrm{x}, r^{2}=0.58, P<0.001$. Regression model for total leaves: $\mathrm{y}=0.296+0.124 \mathrm{x}, r^{2}=0.63, P<0.001$.

$(n=5)$ were used for anthocyanin concentration measurements. From the 10 remaining, two plants randomly selected at each sampling date were harvested for medium properties measurements. The completely randomized design was used. The significance of the results was tested by analysis of variance ( $F$ test) and regression analyses. The treatments means were compared using the Tukey HSD at $P=0.05$. 


\section{Results and Discussion}

Even when $75 \%$ of peat in a peat-perlite medium was replaced by CGC, plant height, leaf number, and leaf size of croton plants were unaffected, whereas root dry weight was increased at the lowest CGC level (Table 1). Although replacement of peat by CGC did not affect quantitative characteristics of croton foliage growth, there was an effect on foliage color, as plants in media with CGC had more areas colored red in their leaves. The increase of red coloration was proportional to the increase of CGC in the medium (Fig. 1). The phenomenon was more intense in the lower leaves than the apical ones. In the basal leaves the effect was significant (mean separation by Tukey HSD) even at the lowest CGC level (25\% peat replacement), whereas in the middle leaves it was significant when $50 \%$ or more of peat was replaced by CGC, and in the apical ones it was significant when $75 \%$ of peat was replaced.

CGC influenced in a similar way the anthocyanins in the leaves. Increasing the CGC level in the medium resulted in a proportional increase of anthocyanin concentration in the basal, middle, and apical leaves, as well as in the total leaves of the plant. However, the mean comparison indicated that only when $75 \%$ of peat was replaced by CGC was there a significant increase of the anthocyanin concentration, except in the total leaves that the effect was significant and at $50 \%$ peat replacement (Fig. 2). Thus the red coloration was more sensitive to CGC level than the anthocyanin concentration. Possibly other pigments, such as carotenoids that often coexist with anthocyanins in red tissues (Griesbach, 1984), or complex formations of anthocyanins that influence the color (Mulder-Krieger and Verpoorte, 1994), were affected by CGC.

A number of workers have demonstrated that elevated EC of the growth medium reduced the availability of water to plants (Bunt, 1988), and there are reports that a reduction in water availability induced an increase in anthocyanins (Ferreyra et al., 2004; Koonjul et al., 2000). Replacement of peat by CGC increased the EC of the growth medium proportionately at the beginning of the experiment $\left(\mathrm{y}=535+96.8 \mathrm{x}, r^{2}=0.95, P<\right.$ 0.001 ), though without any phytotoxic symptoms on the leaves. During the first $50 \mathrm{~d}$ of culture, the EC of media with CGC was dramatically reduced and reached the level of the control (Fig. 3), because of soluble salt leaching, as shown by Cole et al. (2005). Similar behavior of EC in potting media with composts has been previously reported (Papafotiou et al., 2001a, 2004, 2005; Wang and Blessington, 1990). From the fifth month (150 d) of culture onward, the EC increased in all media and remained at a high level until the end of the experiment. Thus, all media had similar EC values during the culture period, except at the beginning of it, but the latter does not seem possible to have affected the anthocyanin concentration in the leaves. Similar to the EC, Na concentration of the media at the beginning of the experiment was

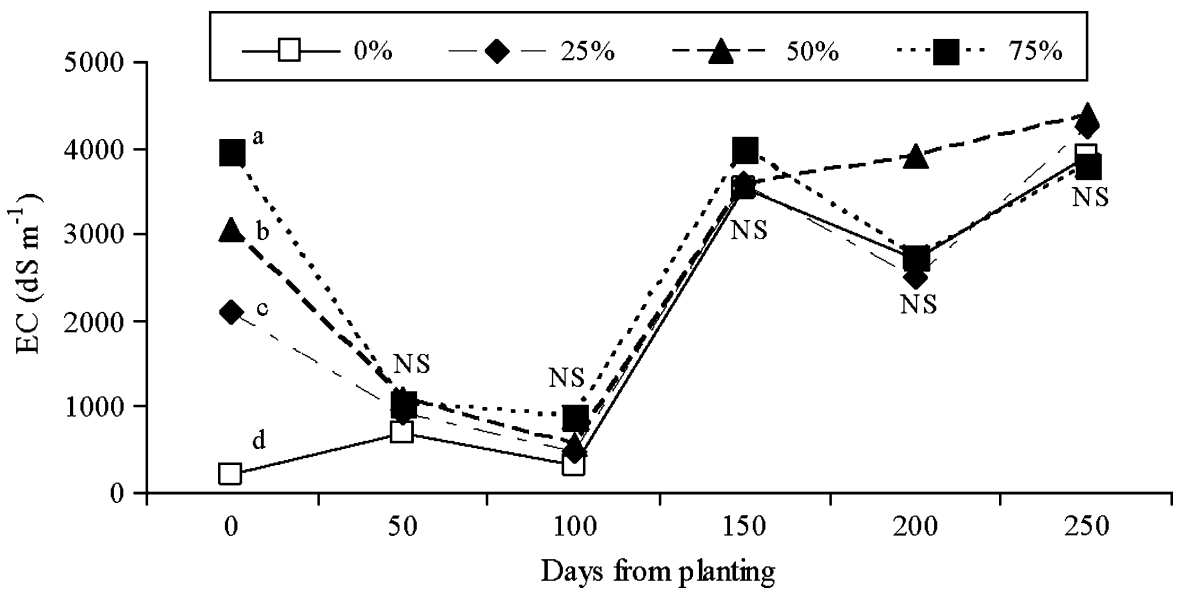

Fig. 3. The effect of peat replacement by cotton gin trash compost at the percentages shown on medium electrical conductance (EC) during the culture period. Mean separation on each sampling day (on column) by Tukey HSD at $P=0.05$.

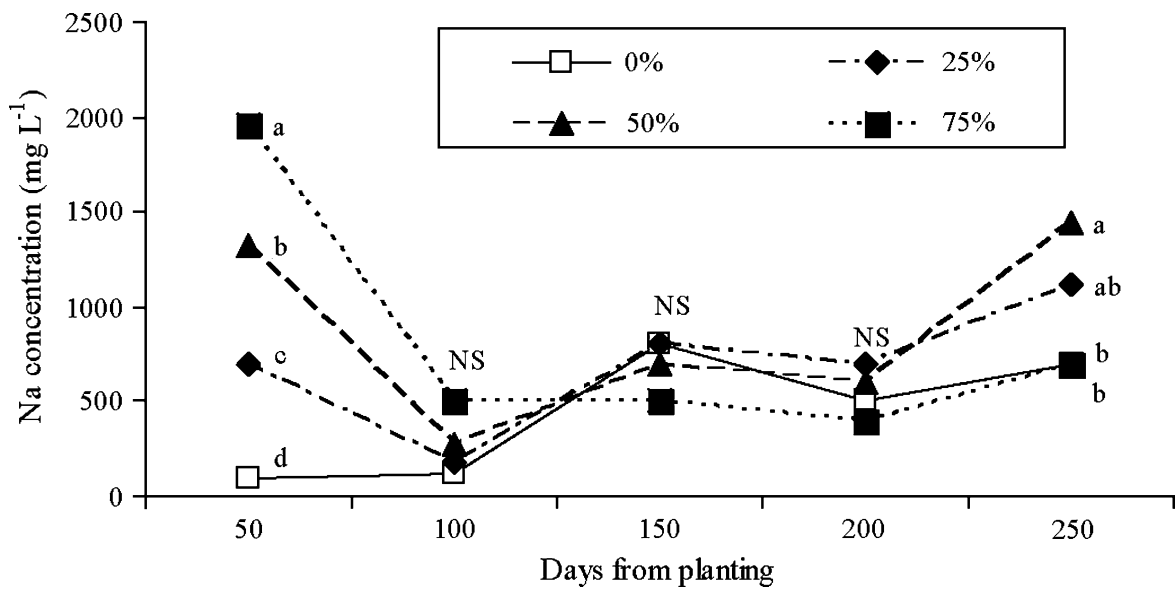

Fig. 4. The effect of peat replacement by cotton gin trash compost at the percentages shown on medium Na concentration during the culture period. Mean separation on each sampling day (on column) by Tukey HSD at $P=0.05$

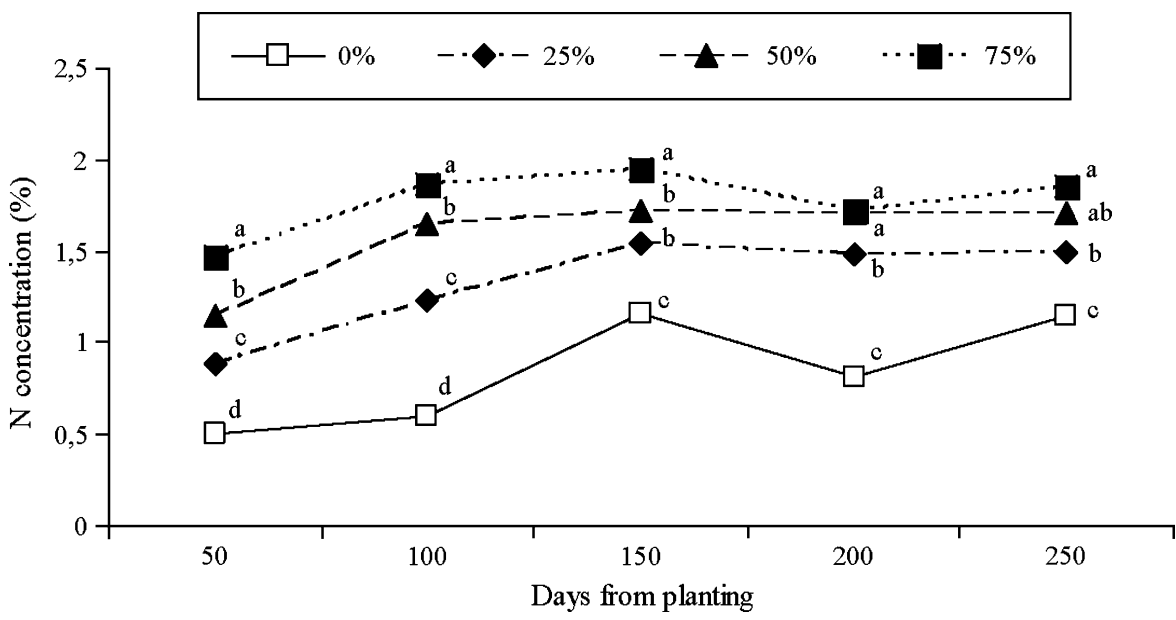

Fig. 5. The effect of peat replacement by cotton gin trash compost at the percentages shown on medium $\mathrm{N}$ concentration during the culture period. Mean separation on each sampling day (on column) by Tukey HSD at $P=0.05$.

analogous to the CGC level $(\mathrm{y}=90+49.6 \mathrm{x}$, $\left.r^{2}=0.999, P<0.001\right)$ : It showed a high decrease in media with CGC after $100 \mathrm{~d}$ of culture, resulting from leaching, and thereaf- ter all media had similar $\mathrm{Na}$ concentrations (Fig. 4). Only at the final measurement was the medium with $50 \%$ peat replacement found to have increased $\mathrm{Na}$ concentration. 
As shown in Figs. 5, 6, and 7, N, P, and $\mathrm{K}$ concentrations were also analogous to CGC level $\left(\mathrm{y}_{\mathrm{N}}=0.526+0.025 \mathrm{x}, r^{2}=0.985, P<\right.$ $0.001 ; \mathrm{y}_{\mathrm{P}}=234.4+43.272 \mathrm{x}, r^{2}=0.979, P<$ $0.001 ; \mathrm{y}_{\mathrm{K}}=-298+160.16 \mathrm{x}, r^{2}=0.935, P<$ $0.001)$. Media with high CGC level (50\% and $75 \%$ peat replacement) had a very high $\mathrm{K}$ concentration at the beginning, which dropped dramatically during the first $100 \mathrm{~d}$ of culture as a result of leaching (Fig. 7). The increased $\mathrm{N}, \mathrm{P}$, and $\mathrm{K}$ concentrations in the medium does not seem possible to have induced the increase of anthocyanin concentration in the leaves, because there are reports of high levels of N, P, and $\mathrm{K}$ in the soil that had a negative effect on anthocyanin concentration in grapes (Piccaglia et al., 2002; Wade et al., 2004; Yoshida et al., 2002).

Initially, the $\mathrm{pH}$ value of the media was analogous to the CGC level $(\mathrm{y}=5.923+$ $\left.0.036 \mathrm{x}, r^{2}=0.949, P<0.001\right)$. In the media that contained CGC, this relation was maintained during the entire culture period (Fig. $8)$. The control medium showed an increase in $\mathrm{pH}$ up to day 100 of culture, possibly as a result of the dolomitic limestone added for $\mathrm{pH}$ adjustment (Williams et al., 1988). The increased $\mathrm{pH}$ in media with $50 \%$ and $75 \%$ peat replacement by CGC could have contributed to the high anthocyanin concentration and increased red coloration through an effect on the availability of nutrients, as P, Fe, $\mathrm{Al}$ and $\mathrm{Mn}$ the availability of which is decreased or $\mathrm{Mg}$ that its availability is increased at high $\mathrm{pH}$ values (Griesbach, 1984; Peterson, 1981). Excess $\mathrm{Mg}$ increased the anthocyanin concentration in aster (Aster sp. Sungal) flowers (Shaked-Sachray et al., 2002) and cocoplum (Chrysobalanus icaco) leaves (Nissim-Levi et al., 2003), and P deficiency usually increases flavonoid levels (Harborne, 1980). Anthocyanins form complexes with metal ions that influence the color of the plant tissue (Goto and Kondo, 1991; Griesbach, 1984; Takeda et al., 1985). It will be a future target to look into the availability of nutrients in media containing compost and the concentration of nutrients in the leaves or petals of ornamentals grown in such media. Another possibility could be that the increased $\mathrm{pH}$ of media with a high CGC content may lead to increased $\mathrm{pH}$ of the vacuolar sap, which influences complex formations of anthocyanins that affect color of plant tissue (MulderKrieger and Verpoorte, 1994).

It has been found that peat replacement by CGC in a peat-perlite medium induces an increase of bulk density and total solids and a decrease of total porosity and readily available water (Papafotiou et al., 2001b). Media in which a high amount of peat is replaced by CGC hold less water in saturation and drain faster (Papafotiou et al., 2001a). Water stress has been found to induce an increase in anthocyanins (Ferreyra et al., 2004; Koonjul et al., 2000), so the availability of water may also be a reason for the increased anthocyanin concentration in croton plants grown in CGC media, although plants never showed any symptoms of water shortage.

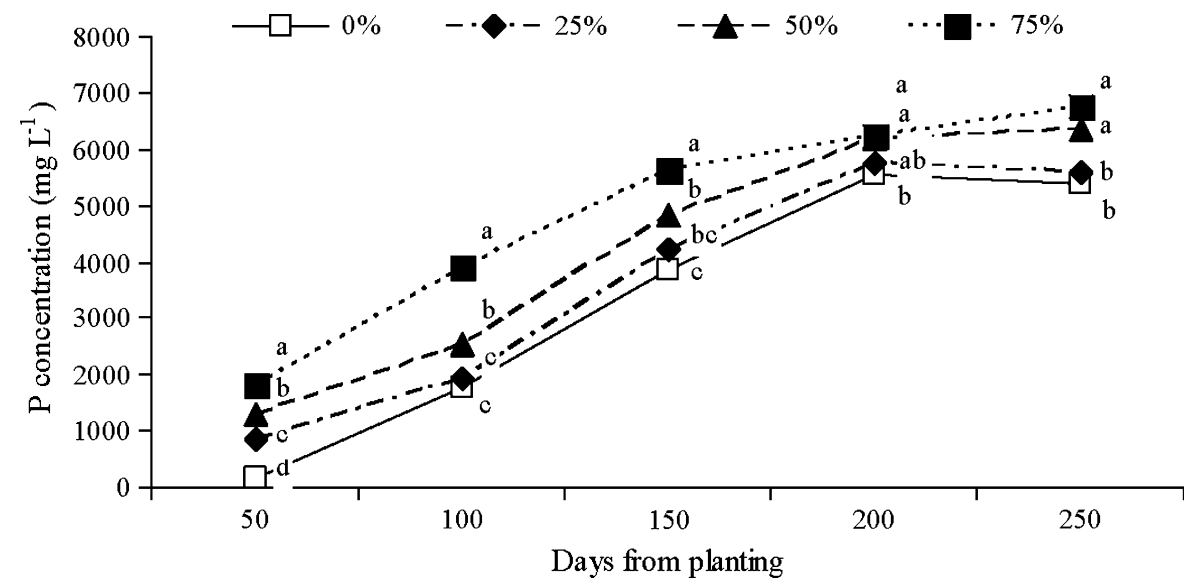

Fig. 6. The effect of peat replacement by cotton gin trash compost at the percentages shown on medium $P$ concentration during the culture period. Mean separation on each sampling day (on column) by Tukey HSD at $P=0.05$.

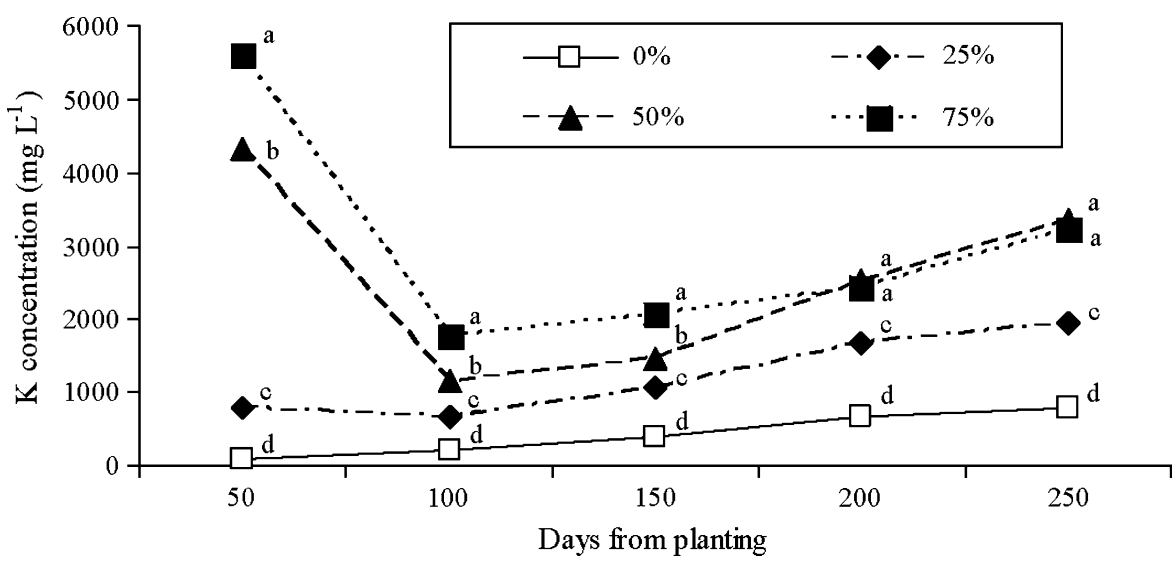

Fig. 7. The effect of peat replacement by cotton gin trash compost at the percentages shown on medium $\mathrm{K}$ concentration during the culture period. Mean separation on each sampling day (on column) by Tukey HSD at $P=0.05$.

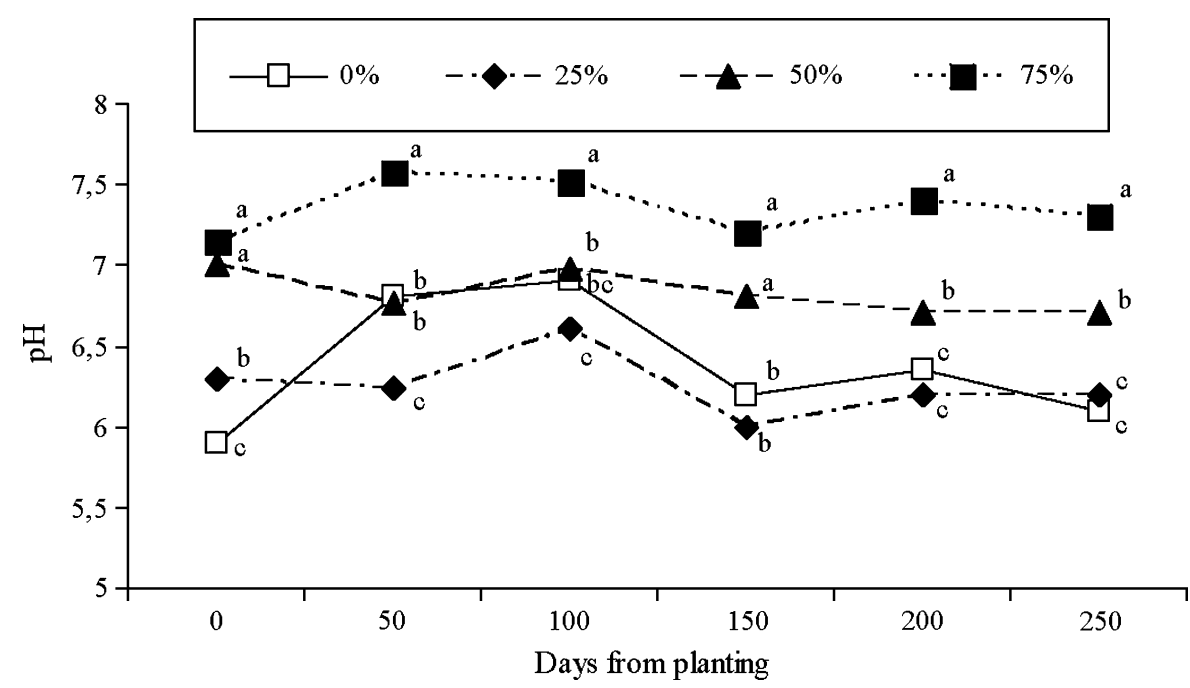

Fig. 8. The effect of peat replacement by cotton gin trash compost at the percentages shown on medium $\mathrm{pH}$ during the culture period. Mean separation on each sampling day (on column) by Tukey HSD at $P=0.05$.

Further experimentation with controlled watering and manipulation of the $\mathrm{pH}$ is needed to determine the factors that affect red pigmentation and anthocyanin concentra- tion in plants grown in media with CGC. The current work suggests that CGC can replace $50 \%$ of peat in a potting medium with perlite, giving croton plants of quality similar to that 
obtained in the commonly used peat-perlite medium. It is to be tested whether the market accepts croton plants with increased red coloration and in such case $75 \%$ of peat could be replaced by CGC. In any case, CGC can replace a considerable amount of peat in the growth medium, and in this way reduce production costs and contribute to the protection of the environment in that an agricultural waste can be disposed of in an environmental friendly way and the need for peat in floriculture can be reduced, thus preserving peat bog ecosystems.

\section{Literature Cited}

Balis, C., F. Flouri, D. Servis, and A. Klidona 1994. Composting of cotton mill wastes for the production of organic fertilizer. Final report of the research project G.S.R.T. The biorefinery: Contribution to the systematic exploitation of agricultural wastes with application to the cotton case. Laboratory of Microbiology, Agricultural University of Athens, Greece.

Bunt, A.C. 1988. Media and mixes for containergrown plants: A manual on the preparation and use of growing media for pot plants. Unwin Hyman, London.

Burger, D.W., T.K. Hartz, and G.W. Forister. 1997. Composted green waste as a container medium amendment for the production of ornamental plants. HortScience 32:57-60.

Cole, D.M., J.L. Sibley, E.K. Blythe, D.J. Eakes, and K.M. Tilt. 2005. Effect of cotton gin compost on substrate properties and growth of azalea under differing irrigation regimes in a greenhouse setting. HortTechnology 15:145-148.

Federal Compost Quality Assurance Organization. 1994. Methods book for the analysis of compost-in addition with the results of the parallel interlaboratory test 1993, p. 1-8. Fed. Compost Qual. Assurance Org., Stuttgart, Germany.

Ferreyra, E.R., V.G. Selles, A.J. Peralta, and B.J. Valenzuela. 2004. Effect of water stress applied at different development periods of Cabernet
Sauvignon grapevine on production and wine quality. Acta Hort. 646:27-33.

Goto, T. and T. Kondo. 1991. Structure and molecular stacking of anthocyanins-flower color variation. Angew. Chem. Int. Ed. Engl. 30:17-33.

Griesbach, R.J. 1984. Effects of carotenoid-anthocyanin combinations on flower color. J. Hered. 75:145-147.

Harborne, J.B. 1980. Plant phenolics, p. 329-402. In: E.A. Bell and B.V. Charlwood (eds). Secondary plant products. Encyclopedia of plant physiology. vol. 8. Springer-Verlag, Berlin.

Harborne, J.B. 1998. Phytochemical methods: A guide to modern techniques of plant analysis. Chapman and Hall, London.

Karam, A. 1993. Chemical properties of organic soils, p. 459-470. In: M.R. Carter (ed.). Soil sampling and methods of analysis. Lewis Publishers, Canadian Society of Soil Science, Boca Raton, Fla.

Koonjul, P.K., W.F. Brandt, G.G. Lindsey, and J.M. Farrant. 2000. Isolation and characterization of chloroplasts from Myrothamnus flabellifolius Welw. J. Plant Physiol. 156:584-594.

McGill, W.B. and C.T. Figueiredo. 1993. Total nitrogen, p. 201-211. In: M.R. Carter (ed.). Soil sampling and methods of analysis. Lewis Publishers, Canadian Society of Soil Science, Boca Raton, Fla.

Mulder-Krieger, T. and R. Verpoorte. 1994. Anthocyanins as flower pigments. Feasibilities for flower color modification. Kluwer Academic Publishers, the Netherlands.

Nissim-Levi, A., S. Kagan, R. Ovadia, and M. Oren-Shamir. 2003. Effects of temperature, UV-light and magnesium on anthocyanin pigmentation in cocoplum leaves. J. Hort. Sci. Biotechnol. 78:61-64.

Papafotiou, M., V. Asimakopoulou, P. Kouvari, I. Kovaeou, M. Phsyhalou, I. Lytra, and G. Kargas. 2001a. Cotton gin trash compost as growing medium ingredient for the production of pot ornamentals. Gartenbauwissenshaft. 66:229-232

Papafotiou, M., J. Chronopoulos, G. Kargas, M Voreakou, N. Leodaritis, O. Lagogiani, and S. Gazi. 2001b. Cotton gin trash compost and rice hulls as growing medium components for ornamentals. J. Hort. Sci. Biotechnol. 76:431435 .

Papafotiou, M., G. Kargas, and I. Lytra. 2005. Olive-mill waste compost as a growth medium component for foliage potted plants. HortScience. 40:1746-1750.

Papafotiou M., M. Phsyhalou, G. Kargas, I. Chatzipavlidis, and J. Chronopoulos. 2004 Olive-mill wastes compost as growing medium component for the production of poinsettia. Sci. Hort. 102:167-175.

Peterson, J.C. 1981. Modify your $\mathrm{pH}$ perspective. Florists Rev. 169:34-35, 92, 94.

Piccaglia, R., M. Marotti, and G. Baldoni. 2002. Factors influencing anthocyanin content in red cabbage (Brassica oleracea var capitata L f rubra (L) Thell). J. Sci. Food Agr. 82:1504 1509.

Shaked-Sachray, L., D. Weiss, M. Reuveni, A. Nissim-Levi, and M. Oren-Shamir. 2002. Increased anthocyanin accumulation in aster flowers at elevated temperatures due to magnesium treatment. Physiol. Plant. 114:559-565.

Stanek, W. and T. Silc. 1977. Comparisons of four methods for determination of degree of peat humification (decomposition) with emphasis on the Von Post method. Can. J. Soil Sci. 57:109-117.

Takeda, K., M. Kariuda, and H. Itoi. 1985. Blueing of sepal color of Hydrangea macrophylla. Phytochemistry 24:2251-2254.

Wade, J., B. Holzapfel, K. Degaris, D. Williams, and M. Keller. 2004. Nitrogen and water management strategies for wine-grape quality. Acta Hort. 640:61-67.

Wang, Y.T. and T.M. Blessington. 1990. Growth and interior performance of Poinsettia in media containing composted cotton burrs. HortScience. 25:407-408.

Williams, B.J., J.C. Peterson, and J.D. Utzinger. 1988. Liming reactions in sphagnum peatbased growing media. J. Amer. Soc. Hort. Sci. 113:210-214.

Yoshida, Y., T. Goto, M. Hirai, and M. Masuda. 2002. Anthocyanin accumulation in strawberry fruits as affected by nitrogen. Acta Hort. 567:357-360 